\title{
Effect of Er:YAG Laser and Sandblasting in Recycling of Ceramic Brackets
}

\author{
Soghra Yassaei ${ }^{1}$, Hossein Aghili ${ }^{1}$, Azadeh Hosseinzadeh Firouzabadi², Hamidreza Meshkani ${ }^{*}$ \\ 'Department of Orthodontics, Faculty of Dentistry, Shahid Sadoughi University of Medical Sciences, Yazd, Iran \\ ${ }^{2}$ Department of Oral Pathology, Faculty of Dentistry, Lorestan University of Medical Sciences, Khorramabad, Iran \\ ${ }^{3}$ Department of Orthodontics, Faculty of Dentistry, Lorestan University of Medical Sciences, Khorramabad, Iran
}

\author{
*Correspondence to \\ Hamidreza Meshkani, MD \\ Department of Orthodontics, Faculty \\ of Dentistry, Lorestan University of \\ Medical Sciences, Khorramabad, \\ Iran. \\ Tel: +98-9151543854 \\ Fax: +98-6633215005 \\ Email: \\ hamidreza.meshkani67@gmail.com
}

Published online 8 January 2017

\begin{abstract}
Introduction: This study was performed to determine the shear bond strength of rebonded mechanically retentive ceramic brackets after recycling with Erbium-Doped Yttrium Aluminum Garnet (Er:YAG) laser or sandblasting

Methods: Twenty-eight debonded ceramic brackets plus 14 intact new ceramic brackets were used in this study. Debonded brackets were randomly divided into 2 groups of 14 . One group was treated by Er:YAG laser and the other with sandblasting. All the specimens were randomly bonded to 42 intact human upper premolars. The shear bond strength of all specimens was determined with a universal testing machine at a crosshead speed of $0.5 \mathrm{~mm} / \mathrm{min}$ until bond failure occurred. The recycled bracket base surfaces were observed under a scanning electron microscope (SEM). Analysis of variance (ANOVA) and Tukey tests were used to compare the shear bond strength of the 3 groups. Fisher exact test was used to evaluate the differences in adhesive remnant index (ARI) scores.

Results: The highest bond strength belonged to brackets recycled by Sandblasting (16.83 $\mathrm{MPa}$ ). There was no significant difference between the shear bond strength of laser and control groups. SEM photographs showed differences in 2 recycling methods. The laser recycled bracket appeared to have as well-cleaned base as the new bracket. Although the sandblasted bracket photographs showed no remnant adhesives, remarkable microroughening of the base of the bracket was apparent.

Conclusion: According to the results of this study, both Er:YAG laser and sandblasting were efficient to mechanically recondition retentive ceramic brackets. Also, Er:YAG laser did not change the design of bracket base while removing the remnant adhesives which might encourage its application in clinical practice.
\end{abstract}

Keyword: Er YAG lasers; Recycling; Brackets; Sandblasting; Shear bond strength; Ceramic brackets.

\section{Introduction}

As a response to esthetic demands of patients, ceramic brackets were designed in mid-1980. Most of ceramic brackets are made of aluminum oxide and based on manufacturing process, divided into 2 groups of polycrystalline and monocrystalline, respectively produced by molding and milling. ${ }^{1,2}$ Due to the neutral nature of the aluminum oxide, chemical bond between the adhesive resin and ceramic is impossible. Therefore the first generation of ceramic brackets was coated by silane to produce a strong chemical bond with adhesive resins. ${ }^{3-5}$ Under debonding forces, the strong chemical bond could result in enamel damages, which became a major concern with the use of these brackets. ${ }^{5,6}$ To overcome this problem the new generation of ceramic brackets were designed with mechanical undercuts on their base. ${ }^{7,8}$ Therefore the chance of enamel fracture during debonding of brackets decreased to clinically acceptable values. ${ }^{7,9}$
Debonding of brackets during treatment period is not uncommon, biting forces and weak bonding are of the main causes.10 Additionally, improper bracket placement may necessitate bracket repositioning. ${ }^{11}$ Due to the brittle nature of ceramic brackets, distortion of the ceramic brackets under debonding forces is unlikely. ${ }^{2,12,13}$ Therefore the intact debonded brackets do not show any changes in the slot dimensions or distortion of the bracket base. Given that, reconditioning of dislodged ceramic brackets without any fracture, instead of using new ones is cost-effective.

Adhesive remnants of dislodged bracket had been conventionally removed by green stones, direct flame, ${ }^{14}$ burning off by a gas torch, ${ }^{15}$ tungsten-carbide bur cleaning, ${ }^{16-18}$ sand blasting ${ }^{3,15,19}$ and silica coating. ${ }^{20}$ In recent years, in a few studies, laser has been used as a bracket recycling method. ${ }^{18,21,22}$ The erbium lasers efficiency in composite removal is well-known and hard tissue application of Er- 
bium-Doped Yttrium Aluminum Garnet (Er:YAG) laser has been approved by the US Food and Drug Administration (FDA). ${ }^{23}$ Based on previous studies, the shear bond strength of recycled brackets was affected by the reconditioning method. ${ }^{11,14,17}$ This study designed to compare Er:YAG laser and sandblasting in recycling of ceramic brackets.

\section{Methods}

Debonded brackets were made according to Chung et $\mathrm{al}^{3}$ study, by bonding thirty mechanically retentive ceramic brackets (Luminous, EMAND ORTHO, Canada) with Transbond XT (3M Unitek, USA) to unetched and slightly wet tooth surfaces. After carefully removing excess bonding material, the brackets were light-cured with a LED curing light (MORITA, Japan) for 20 seconds. Then the brackets were easily debonded from the tooth surface using a tweezer (3M Unitek, USA) and randomly divided into 2 groups.

The laser parameters and cooling methods are showed in Table 1.

Group A: The adhesive removal was performed by an Er:YAG laser device (Fontona-1210 Ljubijana, Slovenia) with $2940 \mathrm{~nm}$ wavelength. A spot size of $0.9 \mathrm{~mm}$ and a $\mathrm{RO} 2-\mathrm{C}$ headpiece were used. The laser was operated on pulse mode (medium short pulse) at a distance of 5-7 $\mathrm{mm}^{24}$ perpendicular to the brackets bases. The average power output was $5.5 \mathrm{~W}$ and laser was used at $275 \mathrm{~mJ}$ and $20 \mathrm{~Hz}$ for 25 seconds with cooling air and water spray. Group B: The brackets were sandblasted (Renfert, Germany) with $50 \mu \mathrm{m}$ aluminum oxide particles at 75 psi for 10 seconds. The brackets bases were held approximately $10 \mathrm{~mm}$ from the sandblaster device.

One bracket was randomly selected from each group and assigned to scanning electron microscope (SEM) examination. Forty-two human upper premolars were extracted within 6 months, collected and immersed in $0.1 \%$ thymol solution, then brushed to remove attached tissues. The samples were randomly divided equally into 3 groups and mounted in wax made boxes by cold-cure acrylic resin.

All teeth were cleaned by prophylactic brush, washed with water and dried. Then the buccal surfaces of the teeth were etched with $38 \%$ phosphoric-acid gel (Fineetch, korea) for 30 seconds, rinsed with water for 10 seconds, and dried

Table 1. The Laser Parameters and Cooling Methods

\begin{tabular}{ll}
\hline Type of Laser & $\begin{array}{l}\text { Fontona-1210 Ljubijana, Slovenia } \\
\text { Er:YAG laser, 2940 nm }\end{array}$ \\
\hline Emission mode & Pulse mode(medium short pulse) \\
Delivery system & Fiber optic \\
Average power & $5.5 \mathrm{~W}$ \\
Spot diameter at focus & $0.9 \mathrm{~mm}$ \\
Focus-to-tissue & $5-7 \mathrm{~mm}$ \\
Water irrigation & $9 \mathrm{~mL} / \mathrm{min}$ \\
& $9 \mathrm{~mL} / \mathrm{min}$ (Manufacture \\
Air and aspirating air flow & $\begin{array}{l}\text { instructions) and } 300 \mathrm{~mL} / \mathrm{min} \\
\text { respectively }\end{array}$ \\
\hline
\end{tabular}

with an oil-free air spray. Next, a thin layer of the Transbond XT primer was applied to the etched enamel. Afterwards, the brackets bases were covered with enough Transbond XT adhesive and placed on the teeth surfaces. After removal of excessive resin around the brackets bases, light curing was performed for 20 seconds with a LED lamp (MORITA, Japan).

\section{Shear Bond Strength Evaluation}

For shear bond strength determination, all specimens were tested with a universal testing machine in shear mode at a crosshead speed of $0.5 \mathrm{~mm} / \mathrm{min}$ until bond failure occurred. During shear bond strength test the buccal surface of the teeth were adjusted parallel to the force vector. Debonding forces were recorded in newton and then converted to megapascal by dividing to the surface area of bracket base.

\section{Scanning Electron Microscope Evaluation}

One recycled bracket from each of the 2 groups and a new bracket were inspected under a SEM (VEGA, TESCAN) at $\times 36$ and $\times 100$ magnification (Figures 1-3).

\section{Adhesive Remnant Index}

After shear bond strength examination, we used a stereomicroscope at $\times 10$ magnification to examine the enamel surface of all samples and the remained adhesives on each one were scored based on adhesive remnant index (ARI) of Oliver. ${ }^{25}$ Score 1 indicated that all adhesive remained on the enamel surface, score 2 indicated that more than $90 \%$ of the adhesive remained on the enamel surface, score 3 revealed that between $10 \%$ and $90 \%$ of the adhesive remained on the enamel surface, score 4 showed that less than $10 \%$ of the adhesive remained on the enamel
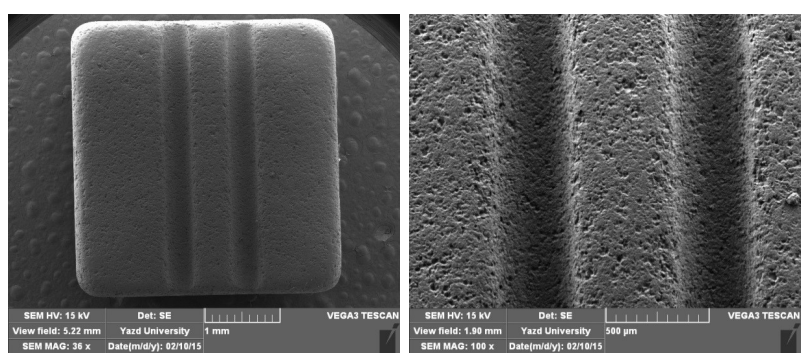

Figure 1. SEM Examination of New Ceramic Bracket (Luminous, EMAND ORTHO, Canada). Left, $\times 36$; right, $\times 100$.
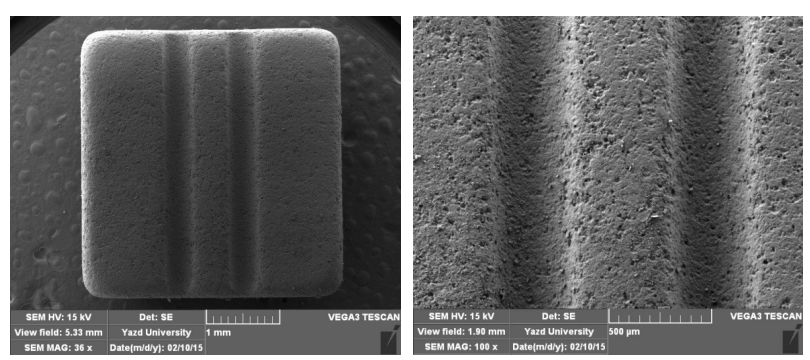

Figure 2. SEM Examination of Laser Recycled Ceramic bracket (Luminous, EMAND ORTHO, Canada). Left, $\times 36$; right, $\times 100$. 

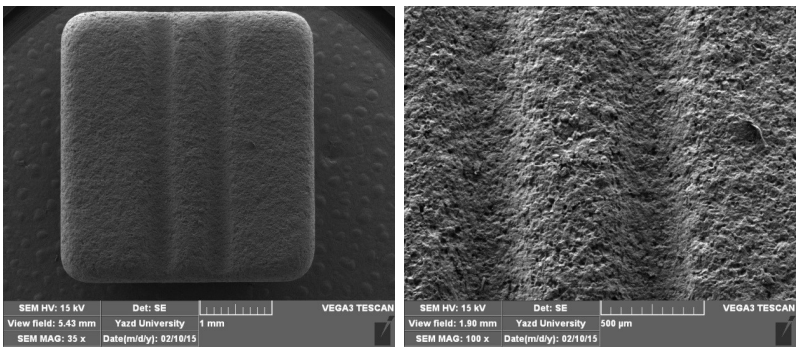

Figure 3. SEM Examination of Sandblasted Ceramic Bracket (Luminous, EMAND ORTHO, Canada) . Left, $\times 35$; right, $\times 100$

surface, and score 5 implied that no adhesive remained on the enamel surface.

Statistical Analysis

All statistical analyzes were performed using the SPSS software 17 (Chicago, USA). The analysis of variance (ANOVA) and Tukey tests were used for comparison of shear bond strength between the three groups. The Fisher exact test was used to evaluate differences in ARI scores. $P \leq 0.05$ was considered significant for all statistical tests.

\section{Results}

The mean shear bond strength and standard deviation (SD) of each group are shown in Table 2. Recycled brackets by sandblasting (group 3) showed the highest bond strength $(16.83 \mathrm{MPa})$. Although brackets recycled by Er:YAG laser had the lowest shear bond strength, there were no significant difference with that of the control group. In the overall analysis of the shear bond strength of the three groups by ANOVA, there was no significant difference $(P=0.001)$. Pairwise comparison by Tukey test showed a significant difference in shear bond strength only between the laser and sandblasting groups (Table 3 ). ARI score for each group is given in Table 4. Bond failure showed a nearly similar pattern. Most samples scored 3 and none of the samples scored 1 or 5 . ARI scores indicate that most of bond failures occurred in a mixed pattern. SEM photographs showed differences between the 2 recycling methods. The laser recycled brackets appeared to have as well-cleaned base as the new bracket (Figures 1 and 2). Although the sandblasted brackets photographs showed no remnant adhesives, remarkable micro-roughening of the bases of the brackets was apparent (Figure 3).

\section{Discussion}

In regard to the increasingly popularity and clinical usage of ceramic brackets, a need for an efficient way to recycle these brackets is felt. This study was designed to evaluate and compare the shear bond strength of recycled mechanically retentive ceramic brackets with sandblasting and Er:YAG laser. The thermal effect of Er:YAG laser is less than other lasers and its abrasive effect on the enamel, dentin, ceramics and composites is different, pertaining to the water content of the material. Er:YAG laser is the laser of choice for dental hard tissue ablation. ${ }^{26}$ During laser radiation it is necessary to use a coolant spray to keep
Table 2. Mean of Shear Bond Strengths of 3 Groups

\begin{tabular}{lcccc}
\hline \multirow{2}{*}{ Group } & \multirow{2}{*}{ No. } & \multicolumn{3}{c}{ Bond } \\
\cline { 3 - 5 } & & Mean (MPa) & SD & Range \\
\hline Control & 14 & 15.31 & 1.77 & $12.24-18.87$ \\
Er:YAG laser & 14 & 13.40 & 2.93 & $8.97-18.59$ \\
Sandblasting & 14 & 16.83 & 1.63 & $14.14-19.63$ \\
\hline
\end{tabular}

Table 3. Pairwise Comparison of Shear Bond Strengths of 3 Groups

\begin{tabular}{llll}
\hline Groups & Control & Laser & Sandblasting \\
\hline Control & - & 0.177 & 0.067 \\
Laser & 0.177 & - & 0.001 \\
Sandblasting & 0.067 & 0.001 & - \\
\hline
\end{tabular}

Table 4. Distribution of ARI Scores

\begin{tabular}{lclllll}
\hline \multirow{2}{*}{ Group } & \multicolumn{7}{c}{ ARI Scores } \\
\cline { 2 - 7 } & $\mathbf{1}$ & $\mathbf{2}$ & $\mathbf{3}$ & $\mathbf{4}$ & $\mathbf{5}$ & $\mathbf{6}$ \\
\hline Control & - & 1 & 10 & 3 & - & - \\
Er:YAG laser & - & 3 & 9 & 2 & - & - \\
Sandblasting & - & 2 & 10 & 2 & - & - \\
\hline
\end{tabular}

Abbreviation: adhesive remnant index.

tissue removal in maximum efficiency without unwanted heat generation. ${ }^{27}$

According to the results of this study, although there were no significant differences among the 3 groups, sandblasted rebonded brackets had the highest mean bond strength $(16.83 \mathrm{MPa})$. Sandblasting has been shown to be efficient to remove any residual material from the bracket base, 28 result in increased micro-roughening of the surface area and wettability of the material, and subsequently increase mechanical retention. ${ }^{29,30}$ SEM photographs of our study, obviously illustrated the micro-roughening of the base of sandblasted brackets. It is worthwhile mentioning that this high bond strength of sandblasted brackets could clinically be a drawback as it could make damages to the enamel surface while debonding. Yim et al evaluated and compared 5 reconditioning methods to recycle metal brackets and ceramic brackets. They used heat treatment, grinding with green stone, sandblasting for four seconds and sandblasting for eight seconds. Either in metal brackets or ceramic brackets, sandblasting for eight seconds had the greatest shear bonding strength, while in ceramic brackets the bonding strength was less than that the control group. ${ }^{15}$

However, in Chung et al study, sandblasted recycled brackets showed almost one-fifth of bond strength of the new brackets. ${ }^{3}$ In another study, which used sandblasting and silica coating to rebond ceramic brackets, the mean bond strength of sandblasted brackets was less than that of either silica coating or control group. ${ }^{23}$ This inconsistency in results might be attributed to the type and quality of ceramics used to make brackets, different manufacturing processes and various mechanical retentions built-in bracket bases. In our view, in cases where mechanical re- 
tention of ceramic bracket was achieved by adding a retentive layer (such as ball-shaped particles) to the bracket base, depending on the method, sandblasting could remove only the retentive layer or roughen the base more. As shown in Table 2, although the mean bond strength of laser recycled brackets was less than the control group, there was no significant difference. SEM photographs showed that Er:YAG laser irradiation was quite efficient in adhesive removal, without any damage to bracket base. This mild reduction in bond strength might be associated to loosely attached adhesive remnants.

Ahrari et al used Er,Cr:YSGG laser to recycle a mechanically retentive ceramic bracket. ${ }^{21}$ Similar to our findings, their results showed that Er,Cr:YSGG laser, another member of Erbium lasers group, was efficient in recycling the ceramic brackets. Ishida et al reported that shear bond strength of metal brackets recycled by Er:Cr:YSGG laser and sandblasting were similar. Based on the SEM photographs, they claimed that Er:Cr:YSGG laser was more efficient to remove adhesive remnants than sandblasting. ${ }^{22}$ Also, Chacko et al. reported that Er:YAG laser recycled metal brackets had significantly greater bond strength than sandblasting group.18 Yassaei et al recycled metal brackets by means of carbon dioxide $\left(\mathrm{CO}_{2}\right)$ laser, Er:YAG laser, sandblasting and direct flaming. According to their results, sandblasting group showed the highest bond strength followed by Er:YAG laser, CO2 laser and direct flame. However, there was no significant difference between sandblasting and Er:YAG laser groups. ${ }^{24}$

Sixty-nine percent of all samples showed ARI Score of 3 indicating $10 \%$ to $90 \%$ of adhesive resin remained on enamel surface. This similarity in ARI score between all groups might be the result of mechanical retentive grooves. Sharp edge angles of retentive grooves localized stress concentration and lead to adhesive failure. ${ }^{31}$ Therefore, after debonding, some of the adhesive remained on the enamel and some of it on the grooved bracket.

\section{Conclusion}

Based on the results of this study the following conclusions were produced:

1. Both Er:YAG laser and sandblasting were efficient to recondition mechanically retentive ceramic brackets.

2. The shear bond strength of brackets recycled with Er:YAG laser and new brackets were not statistically different.

3. SEM photographs showed that laser recycling could effectively remove the adhesives with no damage to the base of bracket, unlike the sandblasting.

4. Although sandblasted brackets showed maximum strength, but the picture has changed the brackets base.

5. Er:YAG laser recycling could provide the brackets with an appropriate shear bond strength which is of clinical use.

6. Most of recycled specimens showed an ARI score of 3 .

\section{Ethical Considerations}

This study has been approved by ethical committee of Shahid Sadoughi University of Medical Sciences.

\section{Conflict of Interests}

There was no conflict of interest to declare.

\section{References}

1. Bishara SE, Fehr DE, editors. Ceramic brackets: something old, something new, a review. Semin Orthod. 1997;3(3):178188.

2. Swartz ML. Ceramic brackets. J Clin Orthod.1988;22(2):82-88.

3. Chung C-H, Friedman SD, Mante FK. Shear bond strength of rebonded mechanically retentive ceramic brackets. Am J Orthod Dentofacial Orthop. 2002;122(3):282-287. doi:10.1067/mod.2002.125994.

4. Britton JC, Mcinnes P, Weinberg R, Ledoux WR, Retief DH. Shear bond strength of ceramic orthodontic brackets to enamel. Am J Orthod Dentofacial Orthop. 1990;98(4):348353. doi:10.1016/S0889-5406(05)81492-1.

5. Bishara SE, Ortho D, Truiove TS. Comparisons of different debonding techniques for ceramic brackets: an in vitro study: Part I. Background and methods. Am J Orthod Dentofacial Orthop. 1990;98(2):145-153.

6. Winchester L. Bond strengths of five different ceramic brackets: an in vitro study. Eur J Orthod. 1991;13(4):293305.

7. Wang WN, Meng CL, Tarng TH. Bond strength: a comparison between chemical coated and mechanical interlock bases of ceramic and metal brackets. Am J Orthod Dentofacial Orthop. 1997;111(4):374-381.

8. Forsberg C, Hagberg C. Shear bond strength of ceramic brackets with chemical or mechanical retention. Brit J Orthod. 1992;19(3):183-9.

9. Harris A, Joseph V, Rossouw P. Shear peel bond strengths of esthetic orthodontic brackets. Am J Orthod Dentofacial Orthop. 1992;102(3):215-219.

10. Lunardi N, Gameiro GH, Magnani MB, et al. The effect of repeated bracket recycling on the shear bond strength of different orthodontic adhesives. Braz J Oral Sci. 2009;7(27):1648-52.

11. Gaffey PG, Major PW, Glover K, Grace M, Koehler JR. Shear/peel bond strength of repositioned ceramic brackets. Angle Orthod. 1995;65(5):351-358.

12. Viazis AD, Chabot KA, Kucheria CS. Scanning electron microscope (SEM) evaluation of clinical failures of single crystal ceramic brackets. Am J Orthod Dentofacial Orthop. 1993;103(6):537-544.

13. Jena AK, Duggal R, Mehrotra A. Physical properties and clinical characteristics of ceramic brackets: a comprehensive review. Trend Biom Artif Organ. 2007;20(2):101-115.

14. Chetan G, Muralidhar Reddy Y. Comparative evaluation of four office reconditioning methods for orthodontic stainless steel brackets on shear bond strength - an in vitro study. Ann Essen Dent. 2011;3(1):6-13.

15. Yim JB, Lee JW, Cha KS. Shear bond strength of recycled orthodontic brackets treated by variable reconditioning methods. Kore J Orthod. 1996;26(5):569-579.

16. Aksu M, Kocadereli I. Influence of two different bracket base cleaning procedures on shear bond strength reliability. J Contemp Dent Pract. 2013;14(2):250-254.

17. Halwai HK, Kamble RH, Hazarey PV, Gautam V. Evaluation and comparision of the shear bond strength of 
rebonded orthodontic brackets with air abrasion, flaming, and grinding techniques: an in vitro study. Orthodontics (Chic.). 2012;13(1):e1-9.

18. Chacko PK, Kodoth J, John J, Kumar K. Recycling stainless steel orthodontic brackets with Er: YAG laserAn environmental scanning electron microscope and shear bond strength study. J Orthod Sci. 2013;2(3):87-94. doi:10.4103/2278-0203.119680.

19. Wendl B, Muchitsch P, Pichelmayer M, Droschl H, Kern W. Comparative bond strength of new and reconditioned brackets and assessment of residual adhesive by light and electron microscopy. Eur J Orthod. 2011;33(3):288-292. doi: 10.1093/ejo/cjq081.

20. Toroglu MS, Yaylali S. Effects of sandblasting and silica coating on the bond strength of rebonded mechanically retentive ceramic brackets. Am J Orthod Dentofacial Orthop. 2008;134(2):181e1-7. doi: 10.1016/j. ajodo.2008.05.012.

21. Ahrari F, Fekrazad R, Kalhori KA, Ramtin M. Reconditioning of ceramic orthodontic brackets with an Er, Cr: YSGG laser. Lasers Med Sci. 2013;28(1):223-8. doi:10.1007/s10103-012-1093-4.

22. Ishida K, Endo T, Shinkai K, Katoh Y. Shear bond strength of rebonded brackets after removal of adhesives with Er, Cr: YSGG laser. Odontology. 2011;99(2):129-34. doi:10.1007/ s10266-011-0012-7.

23. Geraldo-Martins VR, Tanji EY, Wetter NU, Nogueira RD,
Eduardo CP. Intrapulpal temperature during preparation with the Er: YAG laser: an in vitro study. Photomed Laser Therap. 2005;23(2):182-186.

24. Yassaei S, Aghili H, Khan Payeh E. Comparison of shear bond strength of rebonded brackets with four methods of adhesive removal. Lasers Med Sci. 2014;29(5):1563-1568. doi:10.1007/s10103-013-1310-9.

25. Oliver R. The effect of different methods of bracket removal onthe amount of residual adhesive. Am J Orthod Dentofacial Orthop. 1988;93(3):196-200.

26. Keller U, Hibst R. Effects of Er: YAG laser in caries treatment: a clinical pilot study. Lasers Surg Med. 1997;20(1):32-38.

27. Burkes EJ, Hoke J, Gomes E, Wolbarsht M. Wet versus dry enamel ablation by Er: YAG laser. J Prosth Dent. 1992;67(6):847-851.

28. Quick AN, Harris A, Joseph VP. Office reconditioning of stainless steel orthodontic attachments. Eur J Orthod. 2005;27(3):231-236.

29. Peutzfeldt A, Asmussen E. Silicoating: evaluation of a new method of bonding composite resin to metal. Eur J Oral Sci. 1988;96(2):171-176.

30. Blatz MB, Sadan A, Kern M. Resin-ceramic bonding: a review of the literature. J Prosth Dent. 2003;89(3):268-274.

31. Viazis AD, Cavanaugh G, Bevis RR. Bond strength of ceramic brackets under shear stress: an in vitro report. Am J Orthod Dentofacial Orthop. 1990;98(3):214-221. 